\title{
Evaluation of TRMM Multi-satellite Precipitation Analysis (TMPA) performance in the Central Andes region and its dependency on spatial and temporal resolution
}

\author{
M. L. M. Scheel ${ }^{1,2,3}$, M. Rohrer ${ }^{2}$, Ch. Huggel ${ }^{1}$, D. Santos Villar ${ }^{4}$, E. Silvestre ${ }^{5}$, and G. J. Huffman ${ }^{6}$ \\ ${ }^{1}$ University of Zurich, Department of Geography, Zurich, Switzerland \\ ${ }^{2}$ Meteodat GmbH, Zurich, Technoparkstrasse 1, Switzerland \\ ${ }^{3}$ Humboldt University Berlin, Department of Geography, Berlin, Germany \\ ${ }^{4}$ Universidad Nacional Agraria La Molina, Lima, Peru \\ ${ }^{5}$ SENAMHI, Meteorological and Hydrological Service of Peru, Lima, Peru \\ ${ }^{6}$ Science Systems and Applications, Inc., and NASA Goddard Space Flight Center, Greenbelt, Maryland, USA
}

Received: 29 September 2010 - Published in Hydrol. Earth Syst. Sci. Discuss.: 28 October 2010

Revised: 8 June 2011 - Accepted: 27 June 2011 - Published: 25 August 2011

\begin{abstract}
Climate time series are of major importance for base line studies for climate change impact and adaptation projects. However, for instance, in mountain regions and in developing countries there exist significant gaps in ground based climate records in space and time. Specifically, in the Peruvian Andes spatially and temporally coherent precipitation information is a prerequisite for ongoing climate change adaptation projects in the fields of water resources, disasters and food security. The present work aims at evaluating the ability of Tropical Rainfall Measurement Mission (TRMM) Multi-satellite Precipitation Analysis (TMPA) to estimate precipitation rates at daily $0.25^{\circ} \times 0.25^{\circ}$ scale in the Central Andes and the dependency of the estimate performance on changing spatial and temporal resolution. Comparison of the TMPA product with gauge measurements in the regions of Cuzco, Peru and La Paz, Bolivia were carried out and analysed statistically. Large biases are identified in both investigation areas in the estimation of daily precipitation amounts. The occurrence of strong precipitation events was well assessed, but their intensities were underestimated. TMPA estimates for La Paz show high false alarm ratio.

The dependency of the TMPA estimate quality with changing resolution was analysed by comparisons of 1-, 7-, 15- and 30-day sums for Cuzco, Peru. The correlation of TMPA estimates with ground data increases strongly and almost linearly with temporal aggregation. The spatial aggre-
\end{abstract}

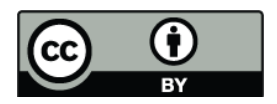

Correspondence to: M. L. M. Scheel (mscheel@alumni.ethz.ch) gation to $0.5^{\circ}, 0.75^{\circ}$ and $1^{\circ}$ grid box averaged precipitation and its comparison to gauge data of the same areas revealed no significant change in correlation coefficients and estimate performance.

In order to profit from the TMPA combination product on a daily basis, a procedure to blend it with daily precipitation gauge measurements is proposed.

Different sources of errors and uncertainties introduced by the sensors, sensor-specific algorithm aspects and the TMPA processing scheme are discussed. This study reveals the possibilities and restrictions of the use of TMPA estimates in the Central Andes and should assist other researchers in the choice of the best resolution-accuracy relationship according to requirements of their applications.

\section{Introduction}

Information about precipitation rates, amounts and distribution is indispensable for a wide range of applications including agronomy, hydrology, meteorology and climatology. The recently launched Swiss Agency for Development and Cooperation (SDC) project "Proyecto de Adaptación al Cambio Climático en el Perú" (PACC) addresses adaptation to climate change on the fields of water resources, disasters and food security in the Peruvian Andes region (Salzmann et al., 2009). This region has been repeatedly recognized as particularly vulnerable to climate change and variability (e.g. Bradley et al., 2006). Spatially and temporally coherent precipitation information is a prerequisite for the related studies.

Published by Copernicus Publications on behalf of the European Geosciences Union. 
The quality of the results of these studies is highly dependent on the quality of the available input precipitation data. Information at high spatial resolution is sparse in most countries because of difficult access, political and financial limitations. Space-borne sensors show good promise to cope with this gap due to their global coverage and increasing temporal and spatial resolution as promoted by the International Global Precipitation Measurement Program (GPM), which follows the current Tropical Rainfall Measurement Mission (TRMM) (Smith et al., 2007). Possibilities provided by the development of new techniques to combine measurements of different space-borne sensors and gauge data allow the derivation of high quality precipitation estimates. Huffman et al. $(1995,1997)$ created a scheme to combine satellite data of different sensors (Microwave [MW], infrared [IR], longwave radiation $[\mathrm{LW}]$ ) with gauge data. The resulting product is the Global Precipitation Climatology Project (GPCP) Combined Precipitation Dataset on a $2.5^{\circ} \times 2.5^{\circ}$ grid in monthly resolution. The further product development resulted in a daily precipitation product on a $1^{\circ} \times 1^{\circ}$ grid, the GPCP OneDegree-Daily (1DD) (Huffman et al., 2001). Xie and Arkin $(1996,1997)$ combined satellite-based estimates from IR and MW, gauge measurements and weather forcast model data with the Climate Prediction Center (CPC) merged analysis of Precipitation (CMAP) to create a new monthly precipitation product on a $2.5^{\circ} \times 2.5^{\circ}$ grid.

Since then, algorithms improved and further multi-source products with higher resolutions emerged. The most important ones which combine measurements from different satellite-borne sensors are the Multi-satellite Precipitation Analysis (TMPA) (Huffman et al., 2007), the only one including radar measurements, the CPC Morphing Technique 7 (CMORPH) (Joyce et al., 2004), the National Environmental Satellite, Data and Information Service (NESDIS) Hydro-Estimator (Scofield and Kuligowski, 2003), the Naval Research Laboratory (NRL) Blended Technique (Turk and Miller, 2005) and the estimation of precipitation using Remotely Sensed Information Using Artificial Neural Networks (PERSIANN) (Sorooshian et al., 2000). All these products are available for (at least) the lower latitudes and the tropics and resolutions about (at least) $0.25^{\circ} \times 0.25^{\circ}$ and 3-hourly. For further information about these precipitation products consult Sapiano and Arkin (2009) for an informative comparison of high resolution satellite-based precipitation estimates and Gruber and Levizzani (2008) for a holistic assessment of global precipitation products.

High-mountain regions are among the most challenging environments for remote-sensing-based precipitation measurements due to extreme topography and high weather and climate variability. At the same time, high-mountain regions are typically characterized by a lack of climate data, which is a drawback for assessing climate change and related impacts. Remote-sensing-derived climate data such as from TRMM could provide an important opportunity to narrow this gap. The TMPA is a combination scheme for pre- cipitation estimates from different space-borne sensors, including microwave, infrared, radar data and gauge measurements. The result is a product with high spatial and temporal resolution (3-hourly, $0.25^{\circ} \times 0.25^{\circ}$ on a longitude-latitude grid) with global coverage between $50^{\circ} \mathrm{N}$ and $50^{\circ} \mathrm{S}$, called TRMM Product 3B42 Research Version 6 (TRMM 3B42 V6; Huffman et al., 2007).

The performance of TRMM 3B42 V6 has been evaluated on various temporal and spatial scales. Su et al. (2008) evaluated TRMM 3B42 V6 for la Plata Basin, South America on daily and monthly scale through comparison with $0.25^{\circ} \times 0.25^{\circ}$ gridded and interpolated gauge data. They found a qualitative agreement of TMPA and gauge data in the occurrence of rain events, but an overestimation of most high precipitation events on a daily scale. They also noted regional variation of TMPA performance. TMPA estimates are significantly better on the monthly scale, but overestimation by the TMPA persists. The authors assign these biases to the "climatological under-catch correction" performed in the processing of TMPA.

A number of studies have used the TRMM 3B42 V6 as an input in hydrological models. Typically, the TMPA performance is assessed with respect to the output of the hydrological model rather than with respect to the precipitation. Wagner et al. (2008), for instance, compared TRMM 3B42 V6 data with precipitation fields generated by the mesoscale meteorological model MM5 and gauge station data for West Africa for 2004 as inputs for hydrological modelling. Verification with gauge data on a monthly scale shows mean overestimation of $12 \%$ ( $-7 \%$ to $29 \%$ ) and a correlation coefficient between 0.67 and 0.92 for the four analyzed regions. However, the TRMM 3B42 V6 data was evaluated as rather low as input to the model, because of high overestimation which is not reflected by the correlation coefficient. A second TRMM data set is produced six to nine hours after data acquisition (real-time version of TRMM 3B42 V6: "TRMM 3B42 RT"), and has also been evaluated for flood prediction (Hazarika et al., 2007).

Huffman et al. (2007) concluded that users could best take advantage of the TMPA resulting product by aggregating the fine scale data to coarser spatial or temporal resolutions according to the requirements of their application. One emerging question is how aggregation in space and time affects the performance of the TMPA data? Or seen from the user's point of view: which spatial and temporal aggregation of the TMPA precipitation estimates provides satisfactory results according to the requirements of my application?

Different scientific and operational applications require different temporal and spatial resolutions. Higher resolutions do not always lead to more accurate results because of the limitations in the available input datasets. More details also reveal more possible error sources.

This paper aims thus to firstly provide a detailed evaluation of the performance of the TMPA precipitation estimates close to the highest resolution $\left(0.25^{\circ} \times 0.25^{\circ}\right.$, daily 

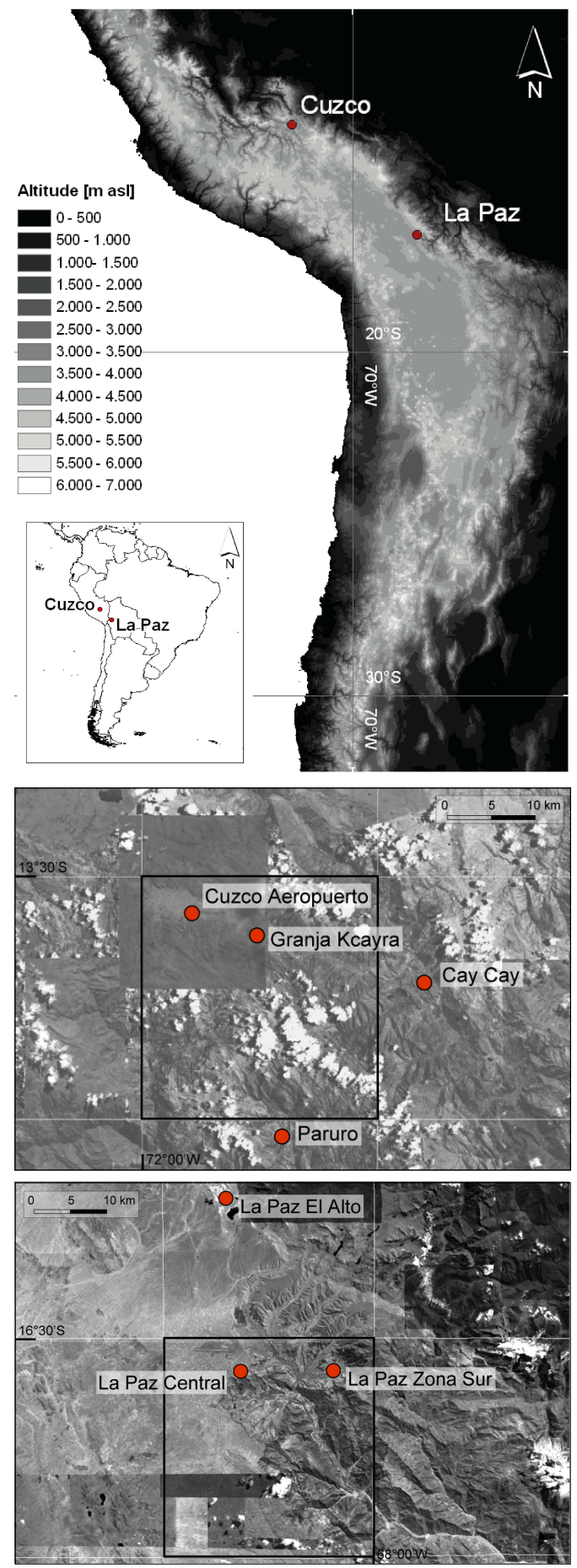

Fig. 1. Map of the Central Andes of South America and the location of the investigation areas Cuzco and La Paz; and depictions of the TRMM tiles for the verifications of daily $0.25^{\circ} \times 0.25^{\circ}$-grid box estimates around (b). Cuzco and (c). La Paz. Both regions show strong topography and high mean altitude characteristic for the Central Andes region. Panels (b) and (c) based on Google Earth ${ }^{\mathrm{TM}}$. precipitation) in the Central Andes, and secondly to assess the TMPA performance at decreasing temporal and spatial scales (3-hourly, daily, 7 days, 15 days, monthly and $0.25^{\circ} \times 0.25^{\circ}, 0.5^{\circ} \times 0.5^{\circ}, 0.75^{\circ} \times 0.75^{\circ}, 1^{\circ} \times 1^{\circ}$ grid boxes). Based on that work, a blending procedure to merge TMPA with precipitation gauge data is tested. Conclusions for potential and limitations of TMPA for hydro-climatic applications are drawn.

\section{Investigation areas and data}

\subsection{Investigation areas}

Two study areas in the Central Andes were selected. The Cuzco region in Peru is the site of several climate change impact and adaptation projects and is typical for the Central Andes in terms of altitude and climate. La Paz was chosen as a second study area with similar topographic and climatic conditions to achieve a broader representativeness of the results and to take advantage of data availability. The location of the study areas is shown in Fig. 1a. Both areas are characterized by a warm-temperate regime with dry winters and wet summers. In the Central Andes about $60 \%$ of the annual precipitation is concentrated in the summer season (December, January, February; Garreaud and Aceituno, 2001). The precipitation in the rainy season is episodic and convective (Garreaud, 1999), resulting in a spatially and temporally variable distribution on small scales. The precipitation regime is furthermore characterized by a high interannual variability driven by the wind patterns on the continental scale (Garreaud and Aceituno, 2001).

The Cuzco region is located in the Central Andes mountain range in the north of the Altiplano. Its cultural, economic and administrative center is the city of Cuzco at an altitude of $3429 \mathrm{~m}$ a.s.l. at $13^{\circ} 53^{\prime} \mathrm{S} 71^{\circ} 96^{\prime} \mathrm{W}$. The strong topography is a major feature of this region (Fig. 1a). Figure $1 \mathrm{~b}$ shows the TRMM tile, and the gauges used for the detailed verification. Mean annual precipitation in Cuzco is about $737 \mathrm{~mm}$ with the monthly maximum in January $(160 \mathrm{~mm})$ and minimum in June (2.4 mm; WMO climate normal period 1961-1990; SENAMHI Peru), resulting in very pronounced wet and dry periods. Figure 1c shows the TRMM tile covering La Paz and the location of the ground stations used for the verification.

The second investigation area is La Paz in Bolivia, situated east of the Altiplano at an altitude of $3734 \mathrm{~m}$ a.s.l. at $16^{\circ} 30^{\prime} \mathrm{S} 68^{\circ} 11^{\prime} \mathrm{W}$. This area is also characterized by strong topography (see Fig. 1a). The mean annual precipitation is slightly lower than in Cuzco, at $602.5 \mathrm{~mm}$, and the rainfall distribution shows a less pronounced seasonal pattern with a maximum of $133.7 \mathrm{~mm}$ in January and a minimum of $5.1 \mathrm{~mm}$ in June (WMO climate normal period 1961-1990; SENAMHI Bolivia). Figure 1c shows the TRMM tile covering $\mathrm{La} \mathrm{Paz}$ and the location of the ground stations used for the verification. 


\subsection{Data}

\subsubsection{Ground Data}

The Peruvian national meteorological and hydrological service, SENAMHI Peru, provides daily precipitation measurements for four conventional stations in Cuzco from 1 January 1998 to 31 May 2008 Fig. 1b shows the location of the stations Cuzco Aeropuerto, Granja Kcayra, Cay Cay and Paruro and the position of the TRMM tile covering this area (TRMM tile extension $13^{\circ} 30^{\prime}-13^{\circ} 45^{\prime} \mathrm{S} / 71^{\circ} 45^{\prime}-72^{\circ} 00^{\prime} \mathrm{W}$ ).

The Bolivian national meteorological and hydrological survey, SENAMHI Bolivia, offers daily precipitation sums for La Paz measured at the conventional stations La Paz Central, La Paz Zona Sur and La Paz El Alto during the period 1 January 2004 to 31 May 2008. All station data was manually quality-checked through comparison with available SYNOP and METAR data. The stations are situated in the northern part of the La Paz TRMM tile (TRMM tile extension $16^{\circ} 30^{\prime}-16^{\circ} 45^{\prime} \mathrm{S} / 68^{\circ} 00^{\prime}-68^{\circ} 15^{\prime} \mathrm{W}$, Fig. 1c).

As shown by the maps, Cay Cay and Paruro (Fig. 1b) and El Alto (Fig. 1c) are not situated within the area covered by the TRMM tiles. Nevertheless, they were included in the comparison to improve the spatial distribution of stations and to provide a more representative dataset for the entire tile area.

\subsubsection{TMPA Data (TRMM 3B42 V6)}

The TRMM Product 3B42 Research Version 6 consists of hourly rainfall rates $\left(\mathrm{mm} \mathrm{h}^{-1}\right)$ at surface level with a global coverage between $50^{\circ} \mathrm{N}$ and $\mathrm{S}$ since 1998 (spatially completed since February 2000). The data is provided in 3hourly intervals on a $0.25^{\circ} \times 0.25^{\circ}$ latitude-longitude grid. It is produced at the NASA Goddard Space Flight Center (GSFC) using TMPA. This method combines precipitation estimates of four passive microwave (PMW) sensors, namely TRMM Microwave Imager (TMI), Special Sensor Microwave/Imager (SSM/I), Advanced Microwave Scanning Radiometer-EOS (AMSR-E) and Advanced Microwave Sounding Unit-B (AMSU-B). These PMW sensors fly on a variety of satellite platforms, namely the TRMM, the Defense Meteorological Satellite Program (DMSP), the Aqua mission and National Oceanic and Atmospheric Administration (NOAA) satellites. They are calibrated with the TRMM Precipitation Radar (PR)-TMI combined instrument product to a high quality (HQ) microwave product. Where HQ microwave data for a certain location and time step is lacking, HQ-calibrated infrared (IR) data, referred to as "variable rain rate" (VAR), is used to fill the gap. The input IR dataset is produced by the Climate Prediction Center (NOAA/CPC; except a Global Precipitation Climatology Project, GPCP, product is used prior to 2000). The $3 \mathrm{~B} 42$ product is composed of calibrated HQ microwave and VAR infrared data in 3-hourly, $0.25^{\circ} \times 0.25^{\circ}$ resolution. Unlike the near-real time version, TRMM 3B42 RT, which is produced approximately six hours after observation time, the TRMM 3B42 V6 is calibrated and merged with ground station data in the monthly resolution and subsequently rescaled to the final 3-hourly intervals (Huffman et al., 2007). The calibrating gauge analysis datasets are processed and provided until March 2005 by the Global Precipitation Climatology Centre (GPCC; GPCP global monthly rain gauge analysis; $1^{\circ}$, monthly) and from April 2005 on by the Climate Assessment and Monitoring System (CAMS Monthly rain gauge analysis; $0.5^{\circ}$ monthly; Su et al., 2008). The TMPA data can be freely downloaded at: http://mirador.gsfc.nasa.gov/ collections/TRMM_3B42_006.shtml. The area covered by one tile of $0.25^{\circ} \times 0.25^{\circ}$ correlates to an area of approximately $25 \mathrm{~km} \times 25 \mathrm{~km}$ in the Central Andes.

It should be noted that TRMM's orbital altitude shifted in August 2001 from 350 to $403 \mathrm{~km}$. More importantly, the available constellation of microwave satellites has varied significantly over time (Huffman et al., 2007).

\section{Uncertainties}

There are different sources of uncertainty inherent in the verification introduced by the ground station data, its validity and independency as ground truth, and the satellite data aggregation process and changes in satellite configurations during the TRMM lifetime. Further uncertainties are introduced by the physical constraints of the satellite sensors and the processing algorithms. They will be addressed in relation to the verification results in the discussion section.

A method to quantify the uncertainty in the verification results which arises from uncertainties in the observation is still a challenge for the scientific community (Ebert, 2007). The assessment of the error in TMPA estimates is one of the most urgent matters in the further development of the TRMM product.

The quality of precipitation data collected by the ground stations as ground truth is difficult to assess. Uncertainties arise from the comparison of a total accumulated over a certain period to the satellite "snapshot" data and from the limited spatial representation of ground measurements (Ebert, 2007). Here we try to account for this variability by using the average of multiple ground stations that are distributed over the satellite tile area. Due to limited availability, the desired homogeneous distribution of stations over the tile area is not always achieved, as shown in Fig. 1c for the La Paz tile. Errors introduced by the concentration of stations in the northern part of the tile cannot be quantified, since there are no other stations in the vicinity of this tile.

Since an arithmetic mean of all available ground station data is constructed, extreme values are reduced, which could be a reason for relatively higher TMPA values. Likewise, the 
number of days without precipitation is likely to decrease. This would imply that the False Alarm Ratio might therefore even be higher than revealed by this verification method.

Uncertainties in the TRMM product are introduced by the 3-h interval of the TMPA estimates and the lack of information between these time steps, especially in regions with very high temporal variability of precipitation such as the Tropics. The entire 3-h interval between estimates is filled by the following value, assuming that this is the best estimate of this interval and that the resulting random error will somewhat cancel over the length of the observation period. We are aware of the problems which are associated with this procedure, but as this work aims to evaluate the ability of the TMPA to estimate the rain rate for further applications, the verification of daily sums constructed using this method seems justified.

The fact that it is impossible to trace back to the stations used in the TMPA processing scheme for the ground calibration is a severe drawback for any verification or application of TMPA data. The full independency of the validation data set is therefore difficult to assure. This work focuses mainly on the performance of daily TMPA estimates and its change with spatial and temporal resolution while the gauge adjustment is done on a monthly basis. Additional to the presented cases we carried out further verifications for the Cuzco region, investigating the estimate performance on daily, weekly, bi-weekly and monthly scale on four further tiles. Their verification shows almost equal results with the cases here presented and thereby increases the representativeness of our results. It is unlikely that the ground truth datasets of all 5 verifications (on a $0.25^{\circ} \times 0.25^{\circ}$ grid) carried out for the Cuzco region each include one ground station on which the calibrating gauge product is based. This is especially unlikely considering that the calibrating gauge product is based on zero to two stations per $2.5^{\circ} \times 2.5^{\circ}$ grid cell in the region.

The change in the satellite altitude from 350 to $403 \mathrm{~km}$ implies changes in the sensor swath width and ground resolution, for which the processing algorithm is supposed to account.

The variable availability of microwave sensors (TMI, different SSM/I and AMSU-B's and from 2004 on AMSR-E (Huffman et al., 2007)) during the TRMM lifetime greatly influences the resulting product as the microwave data is the primary input. However, it is quite difficult to identify the specific input microwave data and the number of samples on which the TMPA values of a certain time, date and location are based. As shown in Fig. 2, some data gaps persist even in the combination of the four microwave sensor types.

\section{Verification methods}

The ground station data for each region was manually quality checked and merged to time series of daily precipitation

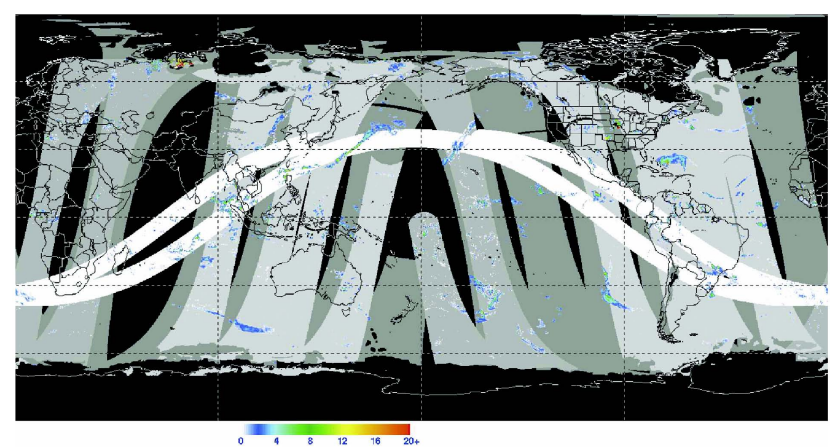

Fig. 2. Example of coverage by TMPA microwave sensors for 25 May 2004, 00:00 UTC. Blacked-out areas denote regions that lack reliable estimates, while the zero values in the remaining areas are colour-coded to depict the coverage by the various sensors. The order of precedence for display and corresponding zero colour are TMI (white), SSM/I (light grey), AMSR-E (medium grey), and AMSU-B (dark grey). Taken from Huffman et al. (2007).

sums by averaging over the relevant TMPA tiles, representing the ground truth for each investigation area. The arithmetic mean has been chosen as the spatial sampling strategy for reasons of data availability, simplicity and working time efficiency. Li and Heap (2008) state in their comparative work of spatial interpolation methods that a sample size smaller than 50 leads to erratic variograms with little or no evident spatial structure. Furthermore they conclude that, besides spatial scale, relative spatial density and distribution of samples; altitudinal and seasonal changes in data play a significant role in the performance of spatial interpolation methods. With the background of the small sample size and the nonhomogeneous distribution, the dependency of the quality of the interpolation results on important factors present in the area, such as strong altitudinal changes and pronounced seasonal patterns, makes the application of more sophisticated interpolation methods unreliable and uncertain. Their use was therefore considered more sensitive to errors in comparison to simple averaging and would increase the uncertainty and lack of transparency. Therefore we selected this rough, simple and widely known method to build spatial means.

To achieve daily precipitation rates, the TMPA estimates in mm-per-hour-resolution and 3-hourly intervals are summed over a day (eight 3-hourly steps; equivalent to local gauge measurements accumulated from 15 to 12 UTC) and multiplied by factor 3 to account for the 3-h interval.

The aim of this verification is to assess the ability of TRMM 3B42 V6 to estimate the amount and occurrence of precipitation events on a daily scale. Furthermore, the change of this ability with decreasing temporal and spatial resolution is examined. As noted above, the verification of the TMPA in the Central Andes is carried out by direct comparisons of daily TMPA precipitation estimates for the tile of Cuzco, Peru and the tile of La Paz, Bolivia to ground 


\begin{tabular}{l|cc} 
& $\begin{array}{c}\text { Gauges } \\
\text { rain }\end{array}$ & $\begin{array}{c}\text { Gauges } \\
\text { no-rain }\end{array}$ \\
\hline $\begin{array}{l}\text { Satellite rain } \\
\text { Satellite no- } \\
\text { rain }\end{array}$ & a & b \\
\end{tabular}

$$
\begin{aligned}
& F B I=\frac{(a+b)}{(a+c)} \\
& F A R=\frac{b}{(a+b)} \\
& P O D=\frac{a}{(a+c)}
\end{aligned}
$$

Fig. 3. Contingency tables used to define categorical measures for the verification of satellite estimates against gauge data. The frequency bias index (FBI) is the ratio of satellite rain estimates to the actual precipitation events. An FBI above 1.0 implicates that the satellite overestimates the number of rain events in the investigation period; a score below 1.0 identifies underestimation. The false alarm ratio (FAR) measures the fraction of false alarms in the satellite rain estimates. The probability of detection (POD) quantifies the fraction of rain events which were correctly estimated by the satellite to the total amount of rain events measured. This result is also known as "hit rate".

measurements performed during 1 January 1998 to 31 May 2008 and 1 January 2004 to 31 May 2008, respectively.

The evaluation is based on statistical analysis and visual interpretation of time series and extreme events. We use the following measures to quantify the overall performance of the TMPA estimates:

Bias calculation assesses the average difference between satellite and gauge value

$\mathrm{BIAS}=\frac{1}{n} \sum_{i=1}^{n}\left(Z^{\mathrm{TMPA}}\left(x_{i}\right)-Z^{\text {gauge }}\left(x_{i}\right)\right)$

where $Z^{\text {TMPA }}$ is the TMPA-estimated precipitation rate, $Z^{\text {gauge }}$ is the corresponding mean of ground measurements and $n$ the number of elements.

Root mean square error (RMSE) measures the average magnitude of the errors with a focus on extreme values.

$\operatorname{RMSE}=\sqrt{\frac{1}{n} \sum_{i=1}^{n}\left(Z^{\mathrm{TMPA}}\left(x_{i}\right)-Z^{\text {gauge }}\left(x_{i}\right)\right)^{2}}$

Pearson's correlation coefficient $r_{x y}$ is a measure for the degree of linear association between the two datasets, but does not consider the magnitude of errors (Ebert, 2007).

$r_{z y}=\frac{\operatorname{Cov}(X, Y)}{\sqrt{\operatorname{Var}(X)} \circ \sqrt{\operatorname{Var}(Y)}}$

Categorical statistics describe the skill of the TMPA in detecting the occurrence of rain and no-rain events, neglecting the errors in the estimation of the amounts of these events. Figure 3 defines the three scores used; Ebert (2007) gives an overview, while a complete description can be found in Wilks (1995). A rain event is given if the ground truth daily precipitation in $\mathrm{mm} \mathrm{d}^{-1}$ is unequal to zero.



Fig. 4. Time series comparison of TRMM 3B42 V6 and gauge daily precipitation for Cuzco, Peru for January to March 2006. The arithmetic mean (horizontal bar), maximum and minimum (vertical bar) of four gauges are plotted in dark blue, while 3B42 V6 is plotted in light blue. The TMPA shows difficulties in the estimation of daily precipitation amounts. A trend of the errors to general over- or underestimation could not be identified.

The analysis of the TMPA not only focuses on the quality of the 3 -hourly, $0.25^{\circ} \times 0.25^{\circ}$ scale, but also on the change of the product quality with different spatio-temporal resolutions. The dependency of the TMPA performance on temporal resolution is analysed by aggregating TMPA data for Cuzco to weekly, 15-days and monthly precipitation sums, calculating Pearson's correlation coefficient, and analyzing extreme events and time series in comparison to the identically aggregated gauge data.

The spatial scales of $0.5^{\circ} \times 0.5^{\circ}, 0.75^{\circ} \times 0.75^{\circ}$ and $1^{\circ} \times 1^{\circ}$ grid box sizes are achieved by aggregation and averaging of TMPA estimates of 4, 9 and 16 neighbouring tiles in the region of Cuzco. They are compared to gauge measurements representative for the respective areas composed by the mean of $4,10,13$ and 17 gauges, respectively, and evaluated using the same statistical measures as for the analysis of the temporal dependency.

\section{Results of TMPA data verification}

\subsection{Verification at daily, $0.25^{\circ} \times 0.25^{\circ}$ grid resolution}

The evaluation of TMPA estimates at daily, $0.25^{\circ} \times 0.25^{\circ}$ grid resolution for the Central Andes showed consistent results for both investigation areas in Peru and Bolivia. The TMPA shows good performance in estimating the occurrence of large precipitation events. The estimation of the magnitude of these events is highly biased as Fig. 4 illustrates for the period January to March 2006. This period is representative of the decade from 1998 to 2008 . Analyses of the errors show no general trend to over- or underestimation. 

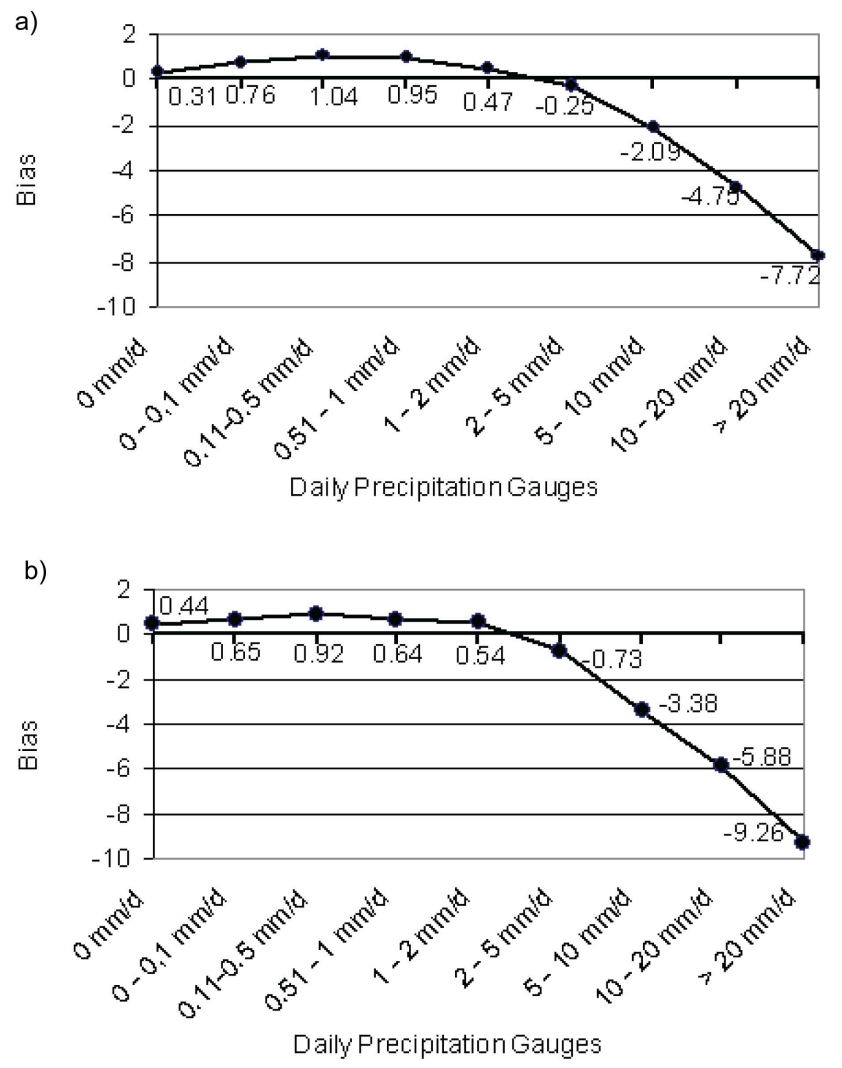

Fig. 5. Bias of TRMM 3B42 V6 versus gauge daily precipitation as a function of the gauge value for 5a Cuzco, Peru, 1 January 1998-31 May 2008, and 5b La Paz, Bolivia, 1 January 200431 May 2008. Both investigation areas show mean underestimation of precipitation rates below $2 \mathrm{~mm} \mathrm{~d}^{-1}$. Above this threshold mean overestimation occurs.

Differentiating between the precipitation rates, however, mean overestimation of small amounts and mean underestimation of amounts exceeding $2 \mathrm{~mm} \mathrm{day}^{-1}$ is found in both regions as shown in Fig. 5a-b.

Table 1 summarizes the statistical verification results. The assessment of dry and wet seasons (dry defined as June, July, August, and wet defined as December, January, February) reveals a seasonal pattern of TMPA performance in both areas. Typically, variance, bias, and RMSE are higher in the wet season due to increased precipitation amounts. The higher frequency of precipitation events furthermore helps explain the low false alarm ratio of this season, which is particularly low in Cuzco. The dry season is characterized by a relatively high false alarm ratio of over $50 \%$ in both regions (56\% for Cuzco, $84 \%$ for La Paz), which is supported by the FBI calculation results. The analyses of detailed contingency tables revealed that $97 \%$ and $89 \%$ of these wrongly estimated values, respectively, are below $3 \mathrm{~mm}$ per day. Pearson's correlation coefficient shows that the association of TMPA data with the ground truth data is higher in the dry season with a stronger discrepancy between the seasons in Cuzco. The total precipitation amounts are very well estimated in the dry periods. In the rainy period the TMPA underestimates the precipitation in both regions. This is consistent with the finding that higher precipitation intensities are generally underestimated.

Analysing high precipitation events reveals that peaks indicated by the ground truth are missed by the TMPA as shown by Fig. 6a-b. The ten highest precipitation events measured in the investigation period were mainly underestimated in both regions. In contrast, the highest TMPA estimates are generally overestimated compared to the amounts measured at the ground, displayed in Fig. 6c-d. Both issues are more pronounced in the Cuzco area.

\subsection{Verification on different temporal resolutions}

The aggregation of TMPA estimates to 7-, 15- and 30-day sums and the comparable ground-data averages for Cuzco showed increasing correlation coefficients with increasing aggregation period length. This result, illustrated by Fig. 7 for the Cuzco tile, is representative for the Cuzco region's estimates as additional verifications with four nearby tiles have showed. Scatterplots show the concentration of points along the 1:1 line at lower resolutions (see Fig. 8a-d). The analysis of time series of 7-, 15- and 30-day sums is presented as an example for the period 1 October 2006 to 30 September 2007 in Fig. 9a-c. These plots confirm that increasing temporal aggregation leads to better agreement between TMPA and the ground truth data. Peaks are progressively better estimated with increasing aggregation periods, but some errors in the estimation of precipitation amounts persist. Figure 9d shows additional TMPA estimate-gauge value points for the entire investigation period on a monthly scale. In general, the TMPA shows a low bias, even though the two data sets are fairly well-correlated.

\subsection{Verification on different spatial resolutions}

Turning to spatial aggregation, TMPA values averaged over $0.5^{\circ} \times 0.5^{\circ}, 0.75^{\circ} \times 0.75^{\circ}$ and $1^{\circ} \times 1^{\circ}$-gridsizes were compared to the mean of $4,10,13$ and 17 gauges respectively, situated within the aggregated areas. The averages for bigger areas show a slightly better linear correlation of TMPA estimates with ground measurements as shown by Fig. 10. In comparison to temporal aggregation, scatter plots of TMPA versus gauge data only show limited improvement for any of the spatial aggregations (see Fig. 11a-d).

\subsection{Verification of hourly values}

A supplementary verification of hourly intensities from Cuzco Airport METAR data with TRMM 3B42 V6 in hourly resolution $(0000,0300,0600,1200,1500,1800,2100$ UTC hours due to availability of product 3B42 in 3-hourly interval) for January to March 2008 was performed. We found the 
Table 1. Overview of statistical verification results of TMPA daily precipitation estimates in comparison to gauge measurements for Cuzco, Peru and La Paz, Bolivia. The rainy season includes the months December, January, February and the dry season includes the months June, July and August. A seasonal pattern in the TMPA performance is found.

\begin{tabular}{|c|c|c|c|c|c|c|}
\hline & \multicolumn{3}{|c|}{ Cuzco 01/01/1998-31/05/2008 } & \multicolumn{3}{|c|}{ La Paz 01/01/2004-31/05/2008 } \\
\hline & Entire period & Rainy season & Dry season & Entire period & Rainy season & Dry season \\
\hline Samplesize & 3804 & 962 & 889 & 1613 & 360 & 368 \\
\hline Total TMPA [mm] & 6906.49 & 3938.57 & 203.37 & 2289.33 & 1067.88 & 95.49 \\
\hline Total Gauges [mm] & 7300.70 & 4226.64 & 199.76 & 2517.12 & 1184.61 & 97.07 \\
\hline Variance TMPA $\left[\mathrm{mm} \mathrm{d}^{-1}\right]$ & 17.74 & 39.94 & 0.78 & 13.46 & 28.74 & 0.83 \\
\hline Variance Gauges [mm d $\left.{ }^{-1}\right]$ & 13.17 & 23.20 & 0.98 & 13.77 & 22.10 & 2.11 \\
\hline Mean TMPA $\left[\mathrm{mm} \mathrm{d}^{-1}\right]$ & 1.82 & 4.39 & 0.23 & 1.42 & 2.97 & 0.26 \\
\hline Mean Gauges $\left[\mathrm{mm} \mathrm{d}^{-1}\right]$ & 1.92 & 4.09 & 0.05 & 1.56 & 3.29 & 0.26 \\
\hline $\operatorname{RMSE}\left[\mathrm{mm} \mathrm{d}^{-1}\right]$ & 3.74 & 5.90 & 0.76 & 3.28 & 5.10 & 1.0 \\
\hline $\operatorname{Bias}\left[\mathrm{mm} \mathrm{d}^{-1}\right]$ & -0.10 & -0.30 & 0.00 & -0.14 & -0.39 & \\
\hline Correlation coefficient & 0.55 & 0.47 & 0.57 & 0.58 & 0.51 & 0.44 \\
\hline FAR & 0.21 & 0.08 & 0.56 & 0.49 & 0.22 & 0.84 \\
\hline FBI & 0.97 & 0.90 & 1.32 & 1.48 & 0.92 & 4.83 \\
\hline POD & 0.76 & 0.83 & 0.61 & 0.76 & 0.72 & 0.75 \\
\hline
\end{tabular}

same qualitative results as in the verification of daily sums regarding the ability of detection of big precipitation events and false alarms. The correlation coefficient was with 0.018 significantly lower than at daily resolution. The lower skill for the shorter interval is consistent with the temporal aggregation results, above. This demonstrates that the performance of the TRMM 3B42 V6 on a daily scale is not the result of the aggregation method.

\subsection{Daily TMPA estimates vs. interpolated precipitation data and blending}

As performance of the TMPA on a daily basis in high Andes regions is rather modest, we tested the use of these estimations as additional information for daily precipitation gauge measurements. All conventional stations posted on the Internet by SENAMHI Peru (SENAMHI Peru, www.senamhi. gob.pe, 2009) for these regions were used. To test the value of TMPA estimates, its performance is compared with a spatial interpolation of gauge values using ordinary Kriging (oK). For November 2005 to April 2006 all precipitation events resulting in daily amounts of more than $5 \mathrm{~mm}$ at 10 stations as a minimum have been selected for interpolation. All interpolation cases have been cross-validated in the larger Cuzco region shown in Fig. 12. The cross-validated values of each daily precipitation event have been correlated with precipitation gauge measurements at the respective stations.

For the next step, a characteristic TRMM tile has been selected for each conventional station. For the selected daily precipitation events a correlation has been calculated for the TMPA-estimated and cross-validated oK-estimated with the gauge-observed precipitation. The results of these two corre- lations for each case are depicted in Table 2, while Figs. 13 and 14 show scatter plots of two selected cases. Daily precipitation gauge measurements from the conventional network of SENAMHI Peru conventional network were compared with estimations by the TMPA. Thirty cases fulfil the mentioned criteria; in eleven cases neither the crossvalidated oK nor the TMPA estimates are at least modestly correlated ( $r<0.5, n=57$ to 59, significance level $\sim 30 \%)$. Analysis of these cases shows that these are highly convective events, which are rather difficult to estimate with either method. In thirteen cases TMPA estimates are at least modestly correlated with gauge measurements. Nine of these cases have higher coefficients of determination than the respective cross-validation performance of oK. In twelve cases $\mathrm{oK}$ is at least modestly correlated with measured values, nine of them being better correlated than TMPA. In one case the TMPA matches the $r^{2}=0.29$ correlation displayed by the oK. As described by Krajewski (1987), it is possible to merge gauge measurements and remote sensing information of precipitation by ordinary cokriging.

An example of a merger by cokriging between gauge values and TMPA estimates is provided in Fig. 15. With cokriging also the correlation between the two variables is considered. The merged map of this rather large event of 15 November 2005, shows clearly the influence of the TMPA-precipitation distribution, especially where station network is sparse. In this case an ordinary cokriging (OCK) algorithm that uses gauge values as the variate and the TMPA as the covariate worked well, as the TMPA values are highly correlated with gauge values. Cases where TMPA values are modestly correlated $(r<\sim 0.8$, significance $<\sim 99.8 \%)$ are problematic, as the performance of blending is poor or 
a)
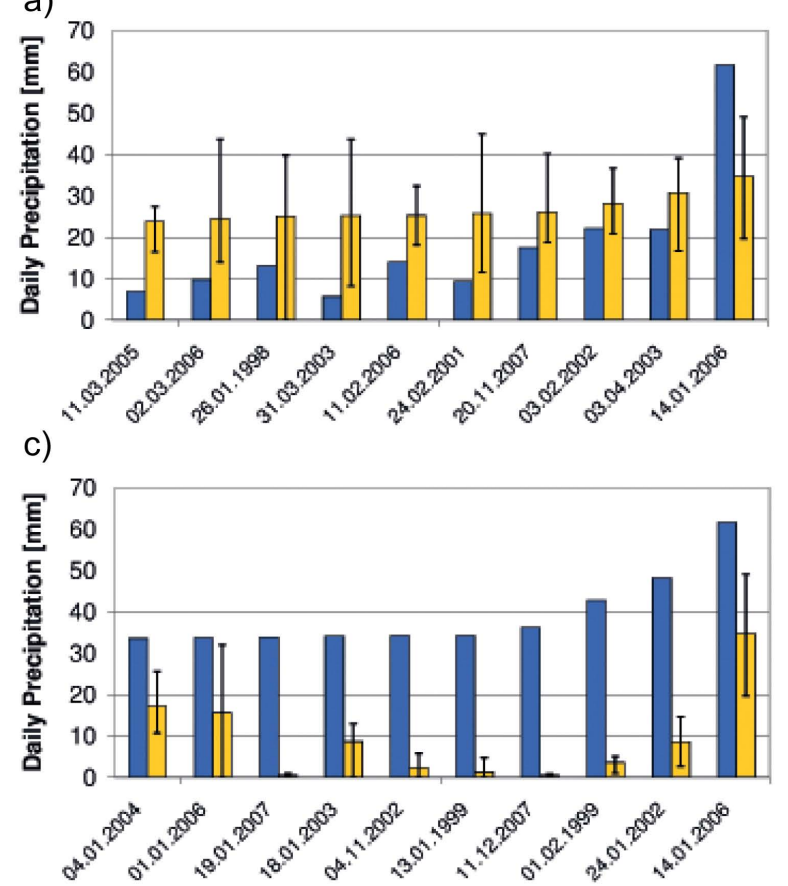

b) 70

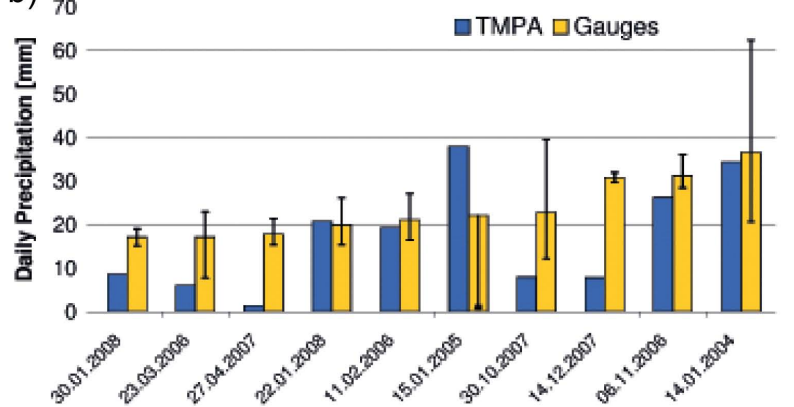

d) 70

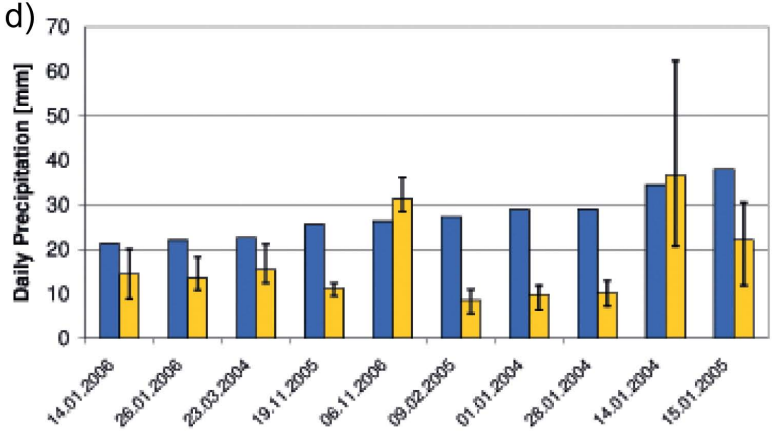

Fig. 6. The ten highest precipitation events registered at the ground and their estimation by the TMPA for (a) Cuzco, Peru, 1 January 199831 May 2008 and (b) La Paz, Bolivia, 1 January 2004-31 May 2008; and (c)-(d) the ten highest daily precipitation sums estimated by the TMPA and equivalent ground values for the same locations and time spans. In addition to the daily mean gauge value (using four gauges for Cuzco and three for La Paz) the minimum and maximum values out of the four (three) gauges are shown as black vertical bars. The TMPA underestimates large precipitation events of the investigation period on one hand, on the other side, the highest TMPA estimates are generally overestimated.

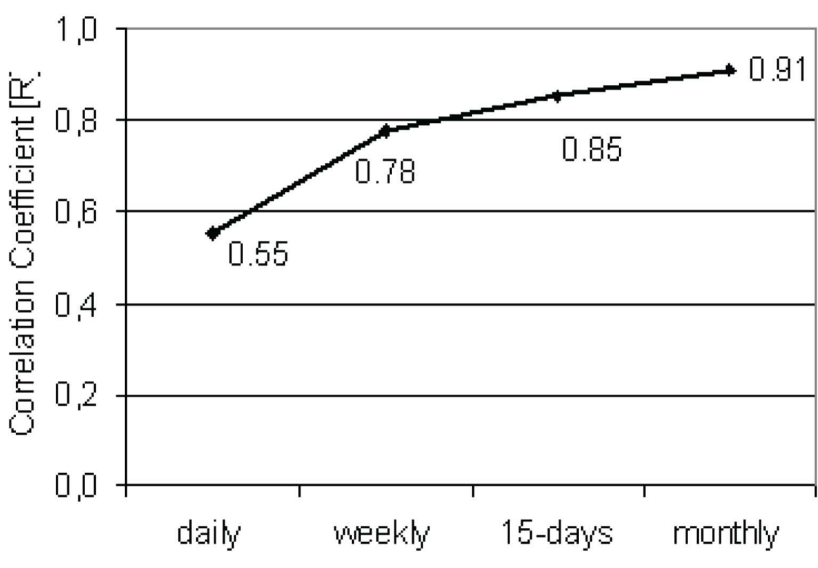

Fig. 7. Linear correlation coefficients between TRMM 3B42 V6 and gauge precipitation data for the single $0.25^{\circ} \times 0.25^{\circ}$ grid box for Cuzco, Peru, as a function of the period of temporal aggregation.

there may even be numerical problems. The latter include mainly rainfall cases with a rather small extent. Therefore, the blending of daily gauge values with TMPA estimates with ordinary cokriging is possible when it is limited to cases where the TMPA-gauge correlation is high and rainfall ex- tent is rather large. Cases, where merging is problematic, are mainly smaller rainfall events, where there is also a considerable area of $0 \mathrm{~mm}$ precipitation. A possible solution could be the usage of ordinary collocated cokriging (OCCK). As Schuurmans et al. (2007) write, OCCK has several advantages over OCK, beside others it avoids instability caused by highly redundant secondary data.

\section{Discussion}

Verification of the TRMM 3B42 V6 in the Central Andes revealed good estimates of monthly precipitation sums provided by gauges. Slight general underestimation of monthly sums in the wet season and consequently in the yearly sums is found. Fifteen-day sums are also fairly well estimated but underestimation has to be considered. The estimation of weekly sums shows less constant performance and decays into a quite variable quality on a daily scale. The estimation errors show no consistent trend, but a general underestimation of higher precipitation and overestimation of low precipitation rates is found. The TMPA shows a high false alarm ratio in the dry season of the Central Andes. The aggregation to coarser spatial resolution does not show sig- 

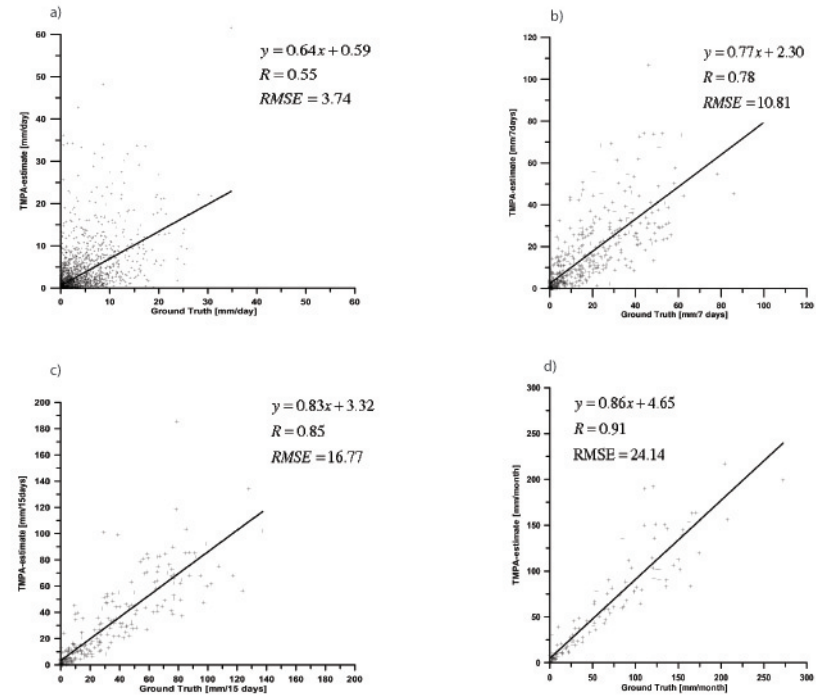

Fig. 8. Scatterplots for TMPA estimates against gauge observations averaged over (a) daily, (b) weekly, (c) 15-day and (d). monthly periods. The data cover the $0.25^{\circ} \times 0.25^{\circ}$ grid box for Cuzco, Peru for January 1998-May 2008. The regression line is plotted in black. Regression line equation, RMSE and correlation coefficient are displayed.

nificantly increased correlation of TMPA with ground measurements.

Possible sources of errors can be identified at the sensor and the product algorithm, as presented above. In general the error analysis is complicated by the difficulty to track errors back to the input data. The upcoming TMPA version 7 is programmed to improve this deficiency. Considering the current limitations, we nevertheless will discuss some of the most important error sources.

Difficulties for space-borne precipitation estimates arise from the geographic characteristics of the investigation area. The Central Andes show rough topography with elevations of $3500 \mathrm{~m}$ a.s.l. and more, and as a consequence, snowfall events can occur and snow cover can persist for a few days. In the highest parts, situated above about $5000 \mathrm{~m}$ a.s.l., glaciated areas can be found (e.g. the Quelccaya ice cap in the Cuzco region). Microwave algorithms over land depend on scattering signals; frozen and icy surfaces cause strong scattering, which leads to estimation difficulties over cold land surfaces and ice- or snow-covered areas (Huffman and Bolvin, 2008). Figure 16 summarizes the microwave brightness temperature signal for precipitation estimates and shows their dependence on surface type. As Ferraro et al. (1998) state, the complicated interaction of earth-emitted microwave radiation with various surface types and atmospheric variables makes the development of surface screens that work very difficult. Moreover in mountainous terrain there is a strong effect of the relief itself on the microwave signal (Mätzler and Standley, 2000), with varying snow cover con-
Table 2. Selected daily precipitation cases from November 2005 to April 2006 in Cuzco. For each case the table shows the coefficient of determination for the correlation between TMPA estimates and measured gauge values and the correlation for ordinary kriging results with gauge measurements (cross-validation).

\begin{tabular}{lrrrrr}
\hline Date & $\begin{array}{r}\text { TMPA- } \\
\text { estimation } \\
r^{2}\end{array}$ & $\begin{array}{r}\text { oK-cross } \\
\text { validation }\end{array}$ & Date & $\begin{array}{r}\text { TMPA- } \\
\text { estimation } \\
r^{2}\end{array}$ & $\begin{array}{r}\text { oK-cross } \\
\text { validation }\end{array}$ \\
\hline 7 Nov 05 & 0.628 & 0.211 & 24 Jan 06 & 0.252 & 0.205 \\
11 Dec 05 & 0.463 & 0.295 & 26 Jan 06 & 0.269 & 0.210 \\
25 Dec 05 & 0.504 & 0.242 & 1 Feb 06 & 0.111 & 0.337 \\
26 Dec 05 & 0.217 & 0.156 & 6 Feb 06 & 0.115 & 0.142 \\
27 Dec 05 & 0.412 & 0.069 & 8 Feb 06 & 0.227 & 0.049 \\
28 Dec 05 & 0.068 & 0.115 & 9 Feb 06 & 0.019 & 0.087 \\
29 Dec 05 & 0.204 & 0.430 & 10 Feb 06 & 0.293 & 0.287 \\
11 Jan 06 & 0.146 & 0.229 & 11 Feb 06 & 0.146 & 0.042 \\
12 Jan 06 & 0.350 & 0.655 & 1 Mar 06 & 0.172 & 0.150 \\
13 Jan 06 & 0.655 & 0.351 & 2 Mar 06 & 0.003 & 0.025 \\
14 Jan 06 & 0.489 & 0.835 & 16 Mar 06 & 0.023 & 0.219 \\
16 Jan 06 & 0.127 & 0.250 & 20 Mar 06 & 0.057 & 0.126 \\
17 Jan 06 & 0.071 & 0.445 & 21 Mar 06 & 0.156 & 0.259 \\
18 Jan 06 & 0.004 & 0.297 & 23 Mar 06 & 0.440 & 0.574 \\
21 Jan 06 & 0.298 & 0.059 & 30 Mar 06 & 0.297 & 0.039 \\
\hline
\end{tabular}

ditions depending on exposure and altitude have a strong influence on brightness temperature and its polarization property (e.g. Amlien, 2008).

Further challenges in the derivation of precipitation estimates from satellite measurements arise from the processing scheme for microwave and IR data. The definition of the underlying surface is very important for the interpretation of the measured microwave signal and globally applied algorithms have to cope with highly heterogeneous terrain with varying brightness temperatures (see also Fig. 16). One problem in IR data processing is that the global algorithms do not consider the altitude of the object. The precipitation is derived indirectly from the brightness temperature at the cloud top (Levizzani et al., 2002). The knowledge of the distance between the cloud top and Earth's surface is important for the estimation of the cell size and its precipitation amount in microwave as in IR data processing. Furthermore, this distance significantly affects the amount of evaporation of rainfall below the cloud base and its ignorance may affect the retrieval accuracy in mountainous terrain (Petty, 2001). Omittance of the surface altitude correction would generally lead to an overestimation of precipitation amount.

Additionally, the indirect character of the retrieval implies that clouds which do not produce any precipitation, as e.g. cirrus clouds in the anvil of convective systems, are included in the IR precipitation estimates.

Furthermore, snow cover and cold air masses may severely affect infrared retrieved estimation of precipitation (Joyce and Arkin, 1997). This fact is particularly important for the study area as explained above. 


\section{a)}
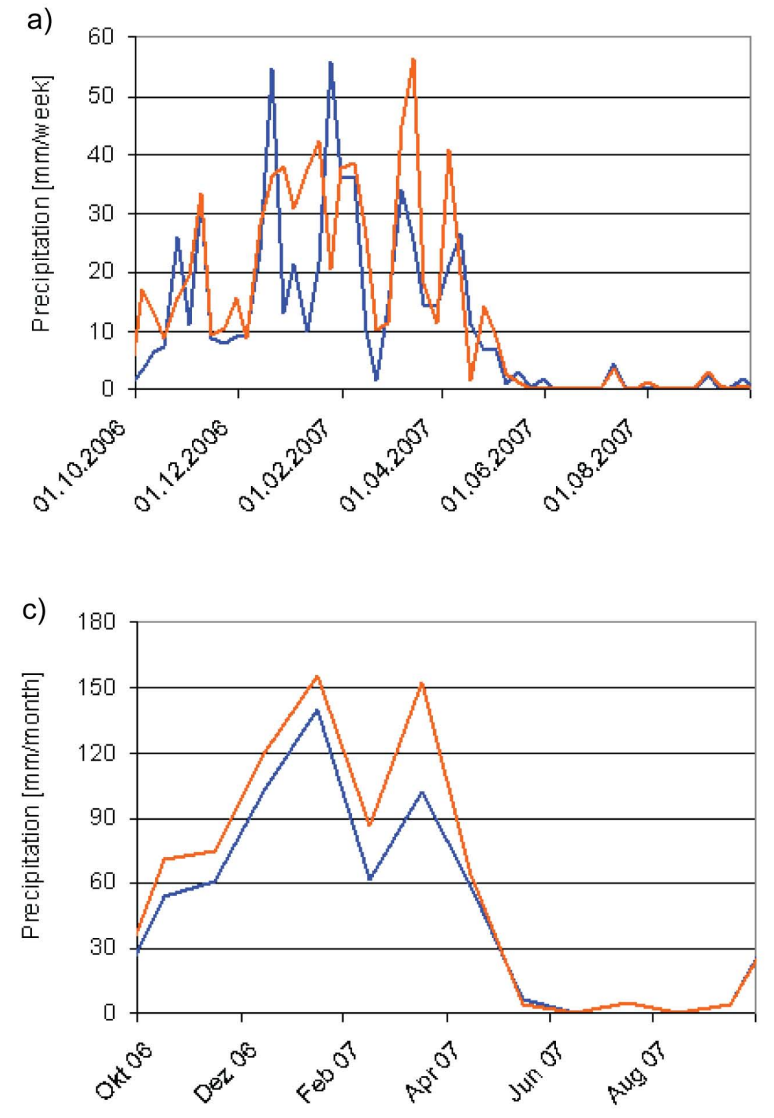

b)

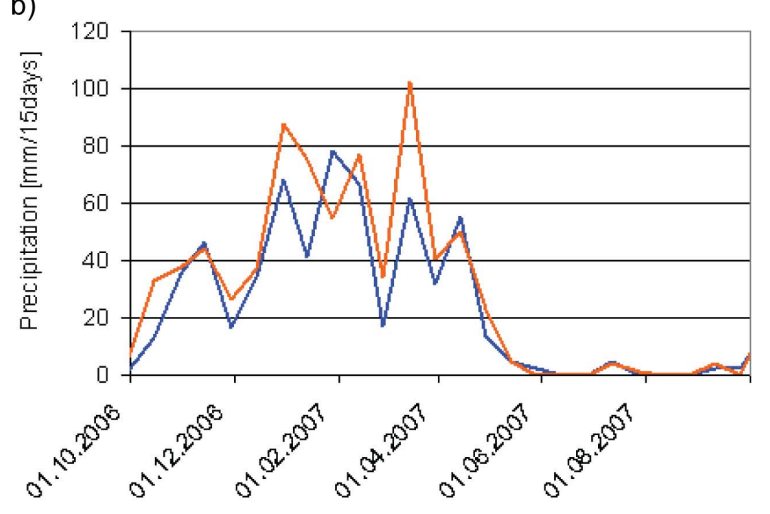

d)

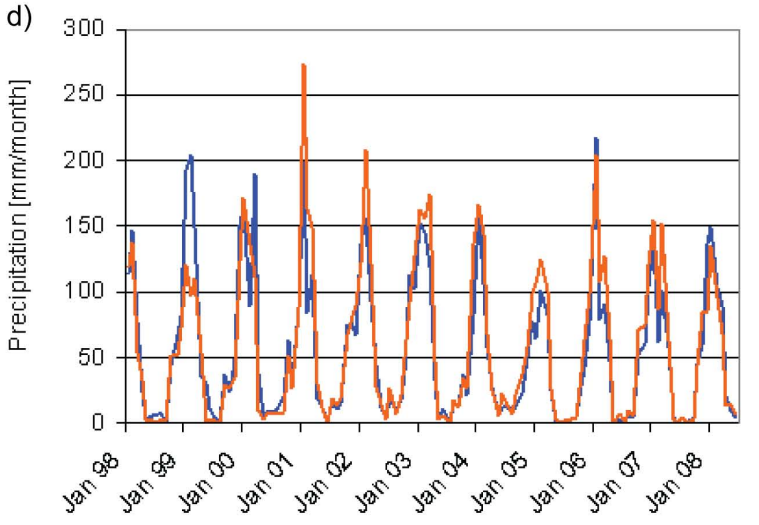

Fig. 9. Time series comparison for TMPA estimates against gauge observations averaged over (a) weekly, (b) 15-day and (c) monthly periods. The data cover the $0.25^{\circ} \times 0.25^{\circ}$ grid box for Cuzco, Peru, the selected period is 1 October 2006-30 September 2007. (d) time series comparison of monthly sums for the entire investigation period January 1998 -May 2008 , tile area of Cuzco in $0.25^{\circ} \times 0.25^{\circ}$ grid resolution. Peaks are progressively well estimated with increasing aggregation periods, but some errors in the estimation of precipitation amounts persist. A general underestimation by the TMPA is found.

On the other hand, Feidas et al. (2008) show that an operational infrared-based precipitation algorithm for the Mediterranean Basin performs as well as $r=0.9$ versus GPCCderived ground truth for July, deteriorating to $r=0.28$ for January. Evidently, infrared derived precipitation estimates are quite viable for convective type precipitation, as is usual in the investigation area, on a monthly time scale when snow and cold air masses are absent.

In the TMPA processing scheme IR data closes the gap if no microwave data is available. The preceding arguments show that the mountainous area in this study imposes one of the most difficult terrains for satellite-based precipitation estimates. As both main data sources, namely microwave and IR, have problems coping with these conditions, data voids and errors are very likely to occur and must be filled with interpolated values which almost certainly have lower skill.

Increasing accuracy for monthly and larger time scales may arise from the TMPA processing algorithm that applies calibration schemes based on monthly histograms. Histogram matching on the monthly scale does not consider the time component of the data, and therefore it does not necessarily improve the individual daily or hourly estimates.

The improvement of TMPA estimates with decreasing spatial resolution was less than expected as (random) errors should diminish by averaging over larger areas. Considering the calibration of TRMM 3B42 V6 with gauge data, the sparsity of the ground data available in the investigated areas must be reflected by the gauge product and its accuracy. As mentioned above, the calibrating gauge data are CAMS on $0.5^{\circ}$, monthly scale starting in May 2005. Until that date the GPCC product on $1^{\circ}$, monthly resolution was used $(\mathrm{Su}$ et al., 2008). The CAMS product in the investigation area is based on zero to two meteorological stations per $2.5^{\circ} \times 2.5^{\circ}$ grid box (Xie et al., 1996). The strong topography of the Central Andes investigation area and the convective nature of precipitation induce a high spatial variability of rainfall distribution. The spatial correlation of stations diminishes with larger distances. Furthermore data policies within GPCC make it impossible to know the input stations used for the calibrating gauge product. We suppose that if any station of the 


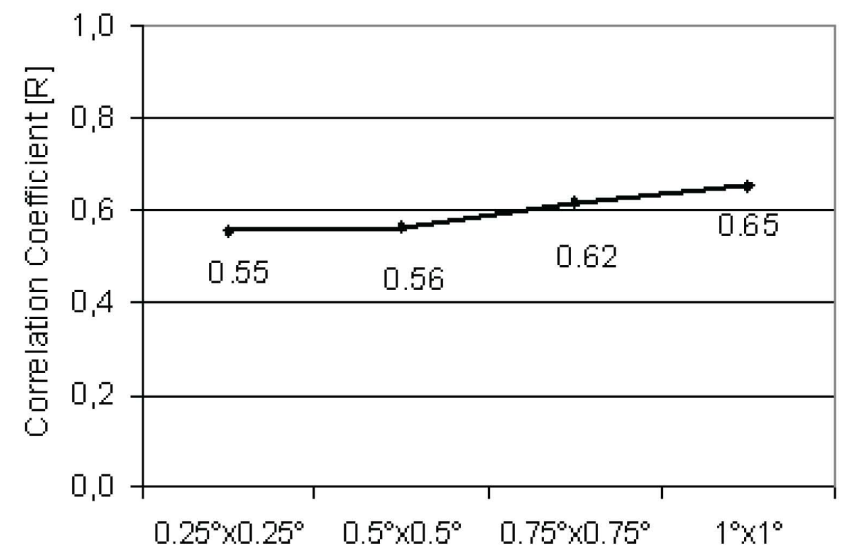

Fig. 10. Linear correlation coefficients between TRMM 3B42 V6 and ground truth precipitation data for Cuzco, Peru, as a function of the area of aggregation. The $0.25^{\circ} \times 0.25^{\circ}, 0.5^{\circ} \times 0.5^{\circ}$, $0.75^{\circ} \times 0.75^{\circ}$ and $1^{\circ} \times 1^{\circ}$-TMPA-grid box averages are correlated to the mean of $4,10,13$ and 17 gauges, respectively.
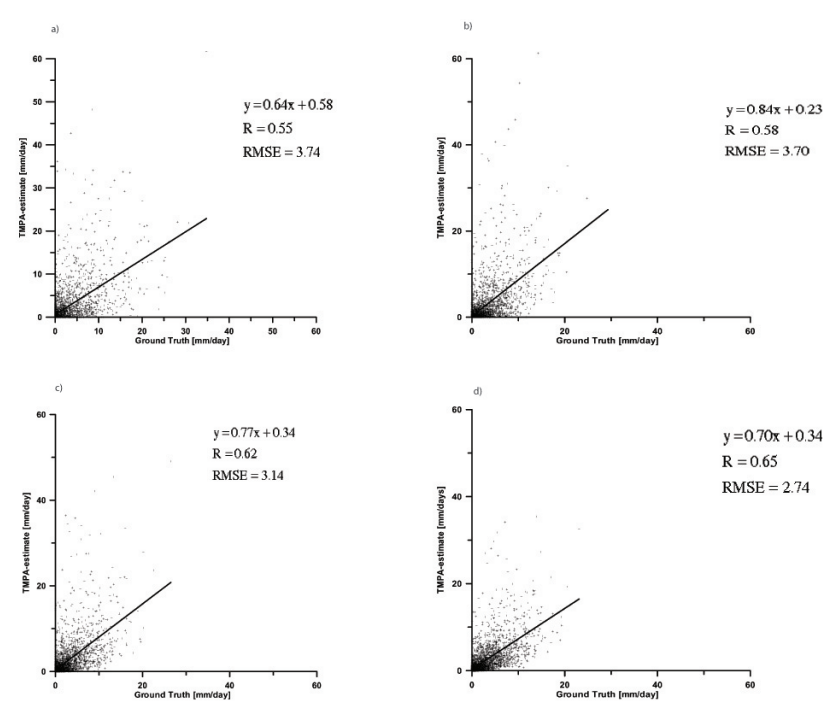

Fig. 11. Scatterplots of mean daily precipitation of TMPA for $0.25^{\circ} \times 0.25^{\circ}, 0.5^{\circ} \times 0.5^{\circ}, 0.75^{\circ} \times 0.75^{\circ}$ and $1^{\circ} \times 1^{\circ}$ grid box averages against gauge measurements. The data cover the $0.25^{\circ} \times 0.25^{\circ}$ grid box for Cuzco, Peru for January 1998-May 2008. The regression line is plotted in black. Regression line equation, RMSE and correlation coefficient are displayed.

region is used in the calibrating CAMS product (GPCC product, respectively), it may be the SYNOP/ METAR station in Cuzco city, covered by the TMPA tile evaluated in the analysis on $0.25^{\circ}$, daily resolution. The calibration with gauge data in areas with low station network density can be considered quite approximate. If the aggregated tiles cover consequently larger areas, the calibration with the gauge product does therefore not necessarily improve the estimates at this spatial scale, as it is not based on more ground stations.



Fig. 12. The region around Cuzco which has been used for crossvalidation of Kriging results and for validation of TMPA estimates.

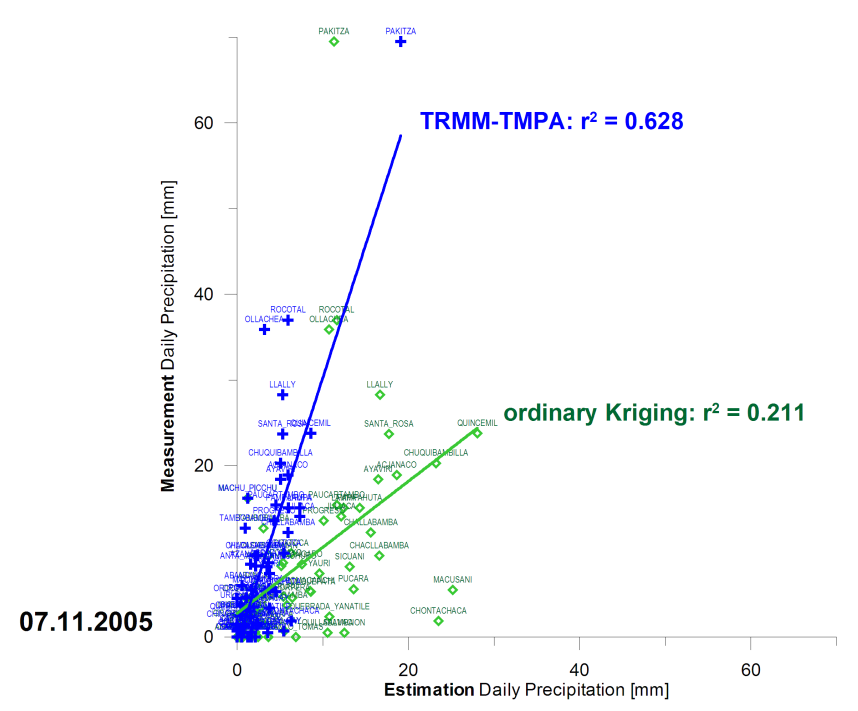

Fig. 13. Rainfall event of 7 November 2005, well estimated by the TMPA. Cross validated values of ordinary Kriging interpolation correlate rather modestly in this event.

Furthermore the larger areas imply that a wider variety of climate zones are sampled, especially as they expand towards the Amazonas, including more humid climatologies and larger altitudinal ranges

The absence of a trend in the bias makes the application of a simple correction factor difficult. In spite of this, the use of correction factors could be considered as an option for hydrological flood warning, noting that a higher hit rate implies a higher false alarm ratio. Another correction possibility is offered by the following finding: if days without rain were estimated with precipitation by the TMPA during the dry season, the incorrectly estimated amount is rather small $\left(<3 \mathrm{~mm} \mathrm{~d}^{-1}\right)$. For instance in the field of agricultural planning, a simple adjustment enables the use of TMPA data to 


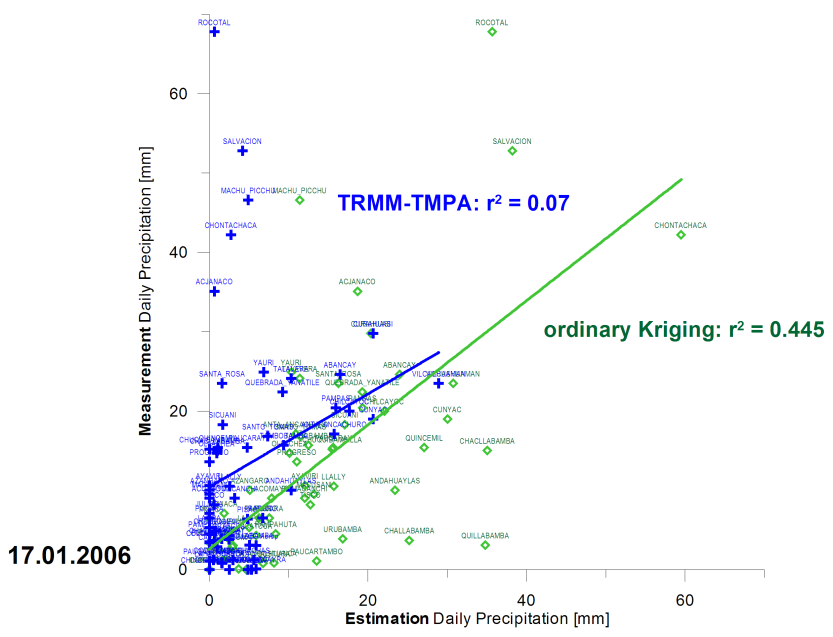

Fig. 14. Rainfall event of 17 January 2006, poorly estimated by TRMM 3B42 V6. In such a case, TMPA combination product is not blended with the daily gauge precipitation values.

determine the dry and the rainy season with sufficient accuracy: Subtracting $3 \mathrm{~mm} \mathrm{~d}^{-1}$ of all TMPA estimates in the dry season eliminates $89 \%$ (La Paz) and $97 \%$ (Cuzco) of the errors, considering the determination of no-rain events.

High temporal resolution applications such as modelling of highly dynamical processes, e.g. run-off or landslides put a premium on the accuracy of precipitation estimates. Since 2008 the Brazilian Weather Service (CPTEC-INPE) has used a novel merging approach of gauges and TRMM-RT for daily precipitation estimation in Southern America (Rozante et al., 2010). They found that such a technique improves daily TRMM-RT estimations considerably.

\section{Conclusions and outlook}

To summarise our results of the TMPA-precipitation assessment for the Cuzco region in Peru and the La Paz region in Bolivia, we conclude that:

1. Generally the correlation coefficients between gauge measurements and TMPA estimates on a $0.25^{\circ} \times 0.25^{\circ}$ basis increase from rather modest values on a daily basis to values of about 0.8 to 0.9 for monthly values.

2. Correlation coefficients between gauge measurements and TMPA estimates show no significant improvement from a $0.25^{\circ} \times 0.25^{\circ}$ to a $1^{\circ} \times 1^{\circ}$ spatial aggregation area.

3. TMPA-based estimations of precipitation are not a replacement for gauge measurements, but an additional source of information, in particular for sparsely gauged regions.

4. The TMPA estimates for both, the Cuzco and the La Paz investigation areas, show - on average - a weak underestimation of middle-size to large daily precipitation amounts and an overestimation for daily sums below $2 \mathrm{~mm} \mathrm{~d}^{-1}$.

5. A blending with the full meteo station network of the Peruvian meteorological and hydrological service (SENAMHI) would improve the quality of the daily TMPA-estimation in the Central Andes region. However, this merging procedure is quite complex if done on an operational basis.

6. Each TMPA value is the result of the combination of products of various input sources. A major problem in interpreting the performance of TRMM 3B42 V6 is the fact that there is no detailed source information accompanying each data value.

7. The results of this study should be carefully taken into account for applications of TMPA data such as for hydrological modelling or landslide early warning. Accuracy is a critical issue for the use of TMPA data with high temporal resolution.

To overcome these problems to a certain degree the following activities are proposed or already in planning phase by several agencies and programs:

1. Starting with Version 7 of the TMPA, source information should accompany each data value.

2. Based on this source information an error estimation scheme as e.g. sketched in Hossain and Huffman (2008) could provide better assessments of the actual quality of TMPA.

3. It is planned to replace the TRMM satellite with a number of new satellites in the framework of the GPM mission. NASA and the Japanese Aerospace Exploration Agency (JAXA) are working together to build and launch the GPM Core Satellite in 2013, providing the calibrator for the entire constellation of microwave satellites that will comprise the heart of the GPM sensor web.

Acknowledgements. We thank the Swiss Agency for Development and Cooperation (SDC) and the Ministry of Environment of Peru for enabling the studies on which this work is based through the Programa de Adaptacion al Cambio Climatico in Peru (PACC) and SENAMHI Peru. We also thank the NASA/Goddard Space Flight Center (NASA/GSFC) for providing the TMPA data on which this study is based.

Edited by: R. Uijlenhoet 

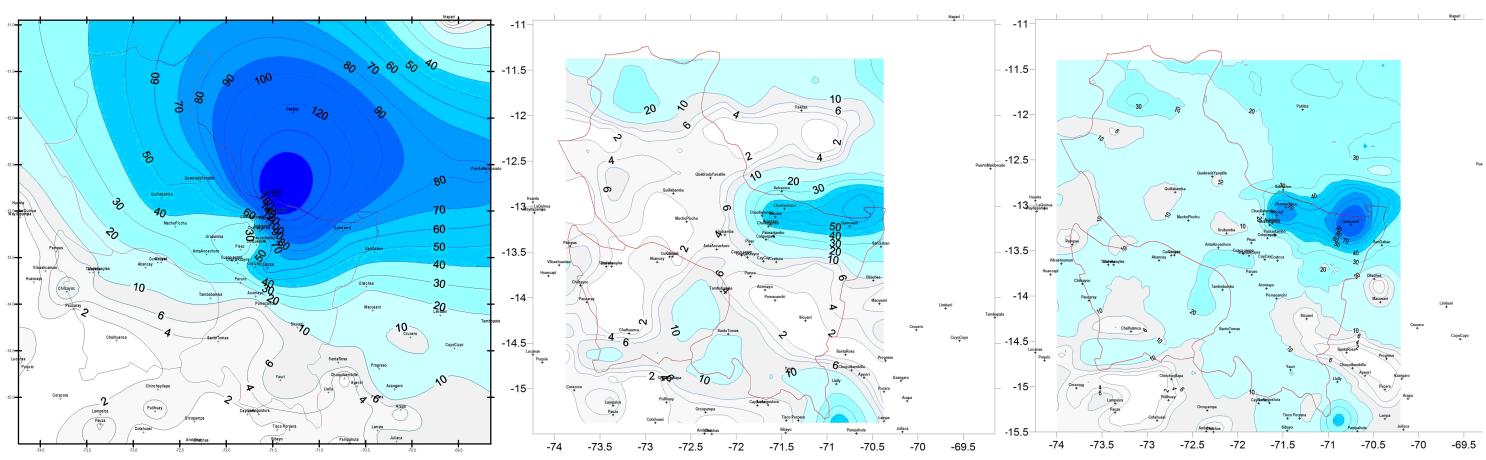

Fig. 15. Interpolated precipitation field in the Cuzco area for the event on 7 November 2005: gauge data alone (left), interpolated TRMM estimations alone (middle) and blended precipitation field with cokriging (right).

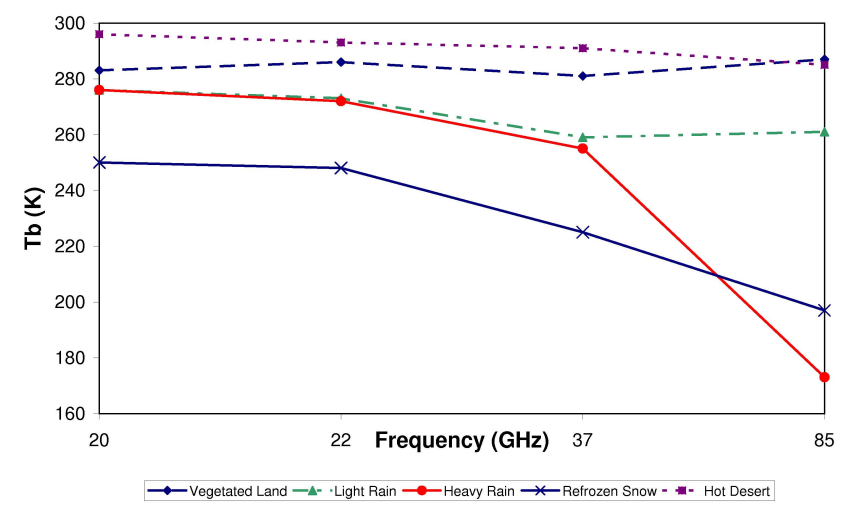

Fig. 16. Brightness temperature variations as a function of frequency for various land surface types. It is obvious that microwave signal as seen from space is strongly dependent on surface type and that certain surface signals are very hardly separable from rain signal (Ferraro et al., 1998, slightly modified).

\section{References}

Amlien, J. (Ed.): Remote sensing of snow with passive microwave radiometers. A review of current algorithms, Report Nr. 1019, Norsk Regnesentral, Oslo, Norway, 52 pp., available at: publications.nr.no/NR-report-1019_snow-PMR.pdf,07/ 05/2010, 2008.

Bradley, R. S., Vuille, M., Diaz, H. F, and Vergara, W.: Climate Change: Threats to Water Supplies in the Tropical Andes, Science, 312, 1755-1756, 2006.

Ebert, E. E.: Methods in verifying satellite precipitation estimates, in: Measuring Precipitation from Space: EURAINSAT and the Future, edited by: Levizzani, V., Bauer, P., and Turk, F. J., Adv. Glob. Change Res., 28, 611-653, Springer, Dordrecht, Netherlands, 2007.

Feidas, H., Kokolatos, G., Negri, A., Manyin, M., Chrysoulakis, N., and Kamarianakis, Y.: Validation of an infrared-based satellite algorithm to estimate accumulated rainfall over the Mediterranean basin, Theor. Appl. Climatol., 95(1-2), 91-109, 2008.

Ferraro, R. R., Smith, E. A., Berg, W., and Huffman, G. J.: A screening methodology for passive microwave precipitation re- trieval algorithms, J. Atmos. Sci., 55, 1583-1600, 1998.

Garreaud, R. D.: Multiscale Analysis of the Summertime Precipitation over the Central Andes, Mon. Weather Rev., 127(5), 901921, 1999.

Garreaud, R. D. and Aceituno, P.: Interannual Rainfall Variability over the South American Altiplano, J. Climate, 14, 2779-2789, 2001.

Goudenhoofdt, E. and Delobbe, L.: Evaluation of radar-gauge merging methods for quantitative precipitation estimates, Hydrol. Earth Syst. Sci., 13, 195-203, doi:10.5194/hess-13-1952009, 2009.

Gruber, A. and Levizzani, V.: Assessment of Global Precipitation Products. A Project of the Global Energy and Water Cycle Experiment (GEWEX) Radiation Panel, World Climate Research Programme (WCRP), 2008.

WCRP-128 WMO/TD-NO. 1430, available at: http://www.wmo.int/pages/prog/wcrp/documents/ AssessmentGlobalPrecipitationReport.pdf, 2 February 2011.

Hazarika, M. K., Kafle, T. P., Sharma, R., Karki, S., Shrestha, R. M., and Samarkoon, L.: Statistical Approach to Discharge Prediction for Flood forecasts using TRMM Data. Proceedings of the 5th Annual Mekong Flood Forum, Ho Chi Minh City, Vietnam, available at: http://www.geoinfo.ait.ac.th/publications.php, 14.11.2008, May 17-18, 2007.

Hossain, F. and Huffman, G. J.: Investigating error metrics for satellite rainfall at hydrologically relevant scales, J. Hydrometeorol., 9, 563-575, 2008.

Huffman, G. J. and Bolvin, D. T.: TRMM and Other Data Precipitation Data Set Documentation, Laboratory for Atmospheres, NASA Goddard Space Flight Center and Science Systems and Applications, Inc., available at: http://disc.sci.gsfc.nasa.gov, 10/02/2009, 2008.

Huffman, G. J., Adler, R. F., Rudolf, B., Schneider, U., and Kehn, P. R.: Global precipitation estimates based on a technique for combining satellite-estimates, rain gauge analysis, and NWP model precipitation estimation, J. Climate, 8, 1284-1295, 1995.

Huffman, G. J., Adler, R. F., Arkin, P., Chang, A., Ferraro, R., Gruber, A., Janowiak, J., McNab, A., Rudolf, B. and Schneider, B.: The Global Precipitation Climatology Project (GPCP) Combined Precipitation Dataset, B. Am. Meteorol. Soc., 78(1), 5-20, 1997.

Huffman, G. J., Adler, R. F., Morrissey, M. M., Bolvin, D. T., Curtis, S., Joyce, R., McGavock, B., and Susskind, J.: Global Precip- 
itation at One-Degree-Daily Resolution from Multisatellite Observations, J. Hydrometeorol., 2, 36-50, 2001.

Huffman, G. J., Adler, R. F., Bolvin, D. T., Gu, G., Nelkin, E. J., Bowman, K. P., Hong, Y., Stocker, E. F., and Wolff, D. B.: The TRMM Multi-satellite Precipitation Analysis (TMPA): Quasiglobal, multiyear, combined sensor precipitation estimates at fine scales, J. Hydrometeorol., 8(1), 38-55, 2007.

Iguchi, T., Kozu, T., Meneghini, R., Awaka, J., and Okamoto, K.: Rain-profiling algorithm for the TRMM precipitation radar, J. Appl. Meteor., 39, 2038-2052, 2000.

Joyce, R. and Arkin, P. A.: Improved estimates of tropical and subtropical precipitation using the GOES Precipitation Index, J. Atmos. Ocean. Tech., 10, 997-1011, 1997.

Joyce, R. J., Janowiak, P., Arkin, P. A., and Xie, P.: CMORPH: A method that produces global precipitation estimates from passive microwave and infrared data at high spatial and temporal resolution, J. Hydrometeorol., 5, 487-503, 2004.

Krajewski, W. F.: Cokriging Radar-Rainfall and Rain Gage Data, J. Geophys. Res., 92(D8), 9571-9580, 1987.

Kubota T., Shige, S., Hashizume, H., Aonashi, K., Takahashi, N., Seto, S., Hirose, M., Takayabu, Y. N., Nakagawa, K., Iwanami, K., Ushio, T., Kachi, M., Okamoto, K.: Global Precipitation Map Using satellite-Borne Microwave Radiometers by the GSMaP Project: Production and Validation, IEEE Trans. Geosci. Remote Sens., 45, 2259-2275, 2007.

Levizzani, V., Amorati, R., and Meneguzzo, F.: A Review of Satellite-based Rainfall Estimation Methods, Multiple-Sensor Precipitation Measurements, Integration, Calibration and Flood Forecasting, Consiglio Nazionale delle Ricerche, Instituto di Scienze dell'Atmosfera e del Clima, Bologna, 2002.

Li, J. and Heap, A. D.: A Review of Spatial Interpolation Methods for Environmental Scientists. Geoscience Australia, Record 2008/23, 137 pp., 2008.

Mätzler, C. and Standley, A.: Relief effects for passive microwave remote sensing, Int. J. Remote Sens., 21, 2403-2412, 2000.

Petty, G. W.: Physical and Microwave Radiative Properties of Precipitation Clouds. Part II: A Parametric 1D Rain-Cloud Model for Use in Microwave Radiative Transfer Simulations, J. Appl. Meteorol., 40, 2115-2129, 2001.

Ropelewski, C. F., Janowiak, J. E., and Halpert, M. S.: The analysis and display of real time surface climate data, Mon. Weather Rev., 113, 1101-1106, 1985.

Rozante, J. R. and Soares Moreira, D.: Combining TRMM and Surface Observations of Precipitation: Technique and Validation over South America, Weather and Forecasting, 25, 885-894, 2010 .
Salzmann, N., Huggel, C., Calanca, P., Diaz, A., Jonas, T., Jurt, C., Konzelmann, T., Lagos, P., Rohrer, M., Silverio, W., and Zappa, M.: Integrated assessment of climate change impacts in Peru, Adv. Geosci., 22, 35-39, 2009, http://www.adv-geosci.net/22/35/2009/.

Sapiano, M. R. P. and Arkin, P. A.: An intercomparison and validation of high-resolution satellite precipitation estimates with 3-hourly gauge data, J. Hydrometeorol., 10(1), 149-166, 2009.

Schuurmans, J. M., Bierkens, M. F. P., Pebesma, E. J., and Uijlenhoet, R.: Automatic Prediction of High-Resolution Daily Rainfall Fields for Multiple Extents: The Potential of Operational Radar, J. Hydrometeorol., 8(6), 1204-1224, 2007.

Scofield, R. A. and Kuligowski, R. J.: Status and outlook of operational satellite precipitation algorithms for extreme precipitation events, Weather Forecast., 18, 1037-1051, 2003.

Smith, E. A.: International Global Precipitation Measurement (GPM) Program and Mission: An overview, in: Levizzani, V., Bauer, P., and Turk, F. J.: Measuring Precipitation from Space: EURAINSAT and the Future. Advances in Global Change Research, 28, 611-653, Springer, Dordrecht, Netherlands, 2007.

Sorooshian, S., Hsu, K., Gao, X., Gupta, H. V., Imam, B., and Braithwate, D.: Evaluation of PERSIANN system satellite-based estimates of tropical rainfall”, B. Am. Meteorol. Soc., 81(9), 2035-2046, 2000.

Su, F., Hong, Y., and Lettenmaier, D. P.: Evaluation of TRMM Multisatellite Precipitation Analysis (TMPA) and its utility in Hydrologic Prediction in the La Plata Basin, J. Hydrometeorol., 9(4), 622-640, 2008.

Turk, F. J. and Miller, S. D.: Toward improved characterization of remotely sensed precipitation regimes with MODIS/AMSRE blended data techniques, IEEE T. Geosci. Remote, 43, 10591069, 2005.

Wagner, S., Kunstmann, H., Bardossy, A., Conrad, C., and Colditz, R. R.: Water balance estimation of a poorly gauged catchment in West Africa using dynamically downscaled meteorological fields and remote sensing information, Phys. Chem. Earth, 34(4-5), 225-235, 2008.

Wilks, D. S.: Statistical Methods in the Atmospheric Sciences: An Introduction, International Geophysics Series, Academic Press, 59, 464, 1995

Xie, P. and Arkin, P. A.: Analyses of Global Monthly Precipitation using Gauge Observations, Satellite Estimates, and Model predictions, J. Climate, 9, 840-858, 1996.

Xie, P. and Arkin, P. A: Global Precipitation: A 17-year monthly analysis based on gauge observations, satellite estimates, and numerical model outputs, B. Am. Meteorol. Soc., 78, 2539-2558, 1997. 